\title{
VERBIPREFIKSID SALATSI LIIVI KEELES
}

\author{
Eberhard Winkler \\ Universität Göttingen
}

\begin{abstract}
Ülevaade. Artikkel käsitleb Salatsi liivi verbiprefiksite esinemist Johann Andreas Sjögreni materjalide põhjal. Arvestades Kuramaa liivi vastavaid uurimusi ja asjaolu, et Sjögreni ajal oli Salatsi liivi juba väljasurev keel, oleks ootuspärane verbiprefiksite arvukas kasutus. Siiski analüüs osutab, et ühelt poolt ei ole verbiprefiksite hulk kuigi suur, teiselt poolt võib neid leida peamiselt kirjalikest tekstidest, mis on otse läti keelest liivi keelde tõlgitud: enamikul juhtudel esinevad verbiprefiksid Salatsi liivi keeles siis, kui need on ka läti keeles. Ühtlasi ilmneb, et verbiprefiksid on küll Salatsi liivis omaks võetud, kuid seda ainult vähesel määral.
\end{abstract}

Märksõnad: verbiprefiksid, liivi keel, Salatsi liivi, Kuramaa liivi

DOI: https://doi.org/10.12697/jeful.2017.8.1.18

1. Nii Kuramaa kui ka Salatsi liivi keeles on lisaks eesti ja ungari keelega sarnastele lahutatavatele verbipartiklitele (nagu näiteks eesti keele ära sööma, välja minema ja ungari keele eljön, megcsinál) olemas ka lahutamatud verbiprefiksid (nii juba SjW II/1: 43-44). Ühelt poolt esineb verbipartikkel näiteks väljendis PRs3sG jera kuolub 'sureb ära', teiselt poolt verbiprefiks aga sõnas isskannat 'välja kannatada'. Verbiprefiksid, nagu üldiselt prefiksid, ei ole aglutineerivatele soomeugri keeltele omased. See tähendab, et (verbi)prefiksid või nende moodustusviis on reeglina kontaktkeeltest üle võetud. Liivi keele puhul pärinevad verbiprefiksid teadupärast läti keelest.

2. Selles kontekstis on olulised 11 läti verbiprefiksit: aiz-, ap-, at-, $i e-, i z-, n o-, p a-, p \bar{a} r-, p i e-, s a-, u z-$. Seitse neist on ka prepositsioonidena läti keeles olemas, "siiski ei ole nende tähendused (verbiprefiksite tähendustega) alati samad" (Forssman 2001: 241); vabade iseseisvate morfeemidena ei tule kunagi ette at-, ie-, iz- ja $s a-$.

Nende prefiksite tähendused läti (Forssman $i b i d$.) ja liivi keeles (SjW II/1: 44-45) on järgmised (vt tabel 1): 
Tabel 1. Prefiksite tähendused läti ja liivi keeles

\begin{tabular}{|c|c|c|}
\hline & LÄTI & LiIVI \\
\hline aiz- & ‘ära’ & ‘ära’ \\
\hline ap- & 'ümber'; sks be- & 'ümber'; sks be-, ver- \\
\hline at- & 'tagasi, juurde’ & 'tagasi, ära'; sks ver-, ent-, er- \\
\hline$i e-$ & 'sisse' & 'sisse' \\
\hline$i z-$ & 'välja' & 'välja, maha'; sks ver-, be- \\
\hline no- & 'maha' & nagu $i z$ \\
\hline$p a-$ & 'välja; pisut' & $\begin{array}{l}\text { (a) deminutiiv 'pisut' } \\
\text { (b) 'suunas' } \\
\text { (c) resultatiivne }\end{array}$ \\
\hline$p \bar{a} r-$ & 'üle’; sks miss- & ‘üle (ka 'ülemäära')' \\
\hline pie- & 'ligi, juurde' & 'ligi, juurde'; sks be-, ver- \\
\hline$s a-$ & 'kokku, lahku' & 'kokku; lahku’; sks ver- \\
\hline$u z-$ & 'peale' & 'peale, ligi, üle, juurde' \\
\hline
\end{tabular}

Läti keeles esinevad nende prefiksite konkreetsed tähendused eriti koos liikumisverbidega (Forssman 2001: 302-303). Neist viit - iz-, $n o-, p a-, s a$ - und $u z-$ - kasutatakse ka lõpetatud tegevuse väljendamiseks. Liivi keele andmed, mis Wiedemann sai verbide tähenduste saksa keelde ülekandmise teel, puudutavad eelkõige Kuramaa liivi keelt, aga nende hulgas on ka piisavalt näiteid Salatsi liivi keele kohta.

3. Kuramaa liivi keele verbiprefiksite kohta on olemas Fanny de Siversi (1971) sünkrooniline analüüs. De Sivers uurimuse aluseks olev ainestik (korpus) koosneb viiest liivi keele lugemikust (vt Ernštreits 2013: 54-70) ning Kettuneni, Mägiste ja Setälä tekstikogudest. Olgu siinkohal mõned de Siversi tulemused (80-82) lühidalt kokku võetud:

a. Kuramaa liivi keel on üle võtnud kõik 11 läti verbiprefiksit.

b. Verbiprefiksite esinemissagedus (78) (vt tabel $2 \mathrm{lk} 351$ ).

c. De Sivers enda korpuses on 351 prefiksverbi, tema arvutuste kohaselt LW-s 490 ja SjW-s (II/2) 291 (78) ${ }^{1}$.

d. Kõiki verbe saab "põhimõtteliselt" kombineerida kõikide prefiksitega (80).

1 LW ja SjW arvude puhul on Salatsi liivi keele prefiksverbidega samuti arvestatud. 
Tabel 2. Verbiprefiksite esinemissagedus de Sivers korpuse ja LW põhjal

$\begin{array}{lrr}\text { no } & 195 & 23,1 \% \\ i z & 131 & 15,5 \% \\ \text { ie } & 97 & 11,5 \% \\ \text { sa } & 95 & 11,0 \% \\ \text { ap } & 66 & 8,0 \% \\ \text { at } & 62 & 7,5 \% \\ \text { pie } & 53 & 6,5 \% \\ \text { uz } & 48 & 6,0 \% \\ \text { pa } & 42 & 5,0 \% \\ \text { pār } & 27 & 3,1 \% \\ \text { aiz } & 25 & 2,9 \% \\ & 841 & \end{array}$

e. Liivi prefiksverbid liiguvad läti eeskujust vabanemise suunas, kuna osal juhtudel ei lange nad vormiliselt või tähenduslikult läti keeles kasutatava mustriga kokku (80).

f. Prefiksid ei ole liivi keeles vältimatult vajalikud. De Sivers (1971: 81): "Mõnedes liivi kirjakeeles kirjutatud tekstides välditakse üleüldse prefikseid ja läti elemente. Siiski võib ka kõnekeel, kus muidu on küll väga palju prefiksverbe, ilma nendeta hakkama saada. Paljude verbide puhul, mida on võimalik üksinda kasutada, kujutab liitvorm endast lihtsalt ilmekamat väljendit. Sealjuures annab prefiks juurde ainult tugevdava varjundi".

4. Prefiksverbide esinemise tingimused välja surnud Salatsi liivi keeles on seevastu seniajani veel üsna segased. Hiljuti avaldatud kõige olulisema Salatsi liivi keele allika, Johann Andreas Sjögreni käsikirjade (Winkler ja Pajusalu 2016) põhjal on nüüd aga võimalik selle keele kohta üksikasjalikke väiteid esitada. Järgnevate selgituste jaoks on arvesse võetud vaid käsikirjades sisalduvaid lauseid (umbes 2180), mitte aga eraldiolevat sõnavaralist materjali. Uurimistulemused võib lühidalt esitada järgmiselt:

a. Sjögreni 2180 lauses esineb prefiksverbe 391 korral. See tähendab, et käsikirjades ei leidu mitte 391 erinevat verbi või prefiksi ja verbi kombinatsiooni, vaid et ära on loendatud kõik prefiksverbide esinemisjuhud. Sealjuures mõned neist esinevad mitmel korral, näiteks pa-tied 
'tegema', at-kost 'vastama' või kõige rohkem (19 korda) ette tulev juht ais-läed 'ära minema' on vastavalt esinemissagedusele mitmekordselt loendatud.

b. Sellest järeldub, et vaevalt iga viies lause (17,9\%) sisaldab prefiksverbi. See kehtib siiski ainult üldistatult, sest mõnedes lausetes esineb korraga mitu prefiksverbi.

c. Kõik 11 läti keele prefiksit esinevad ka Salatsi liivi keeles.

d. Üksikute prefiksite esinemissagedus varieerub kohati äärmiselt palju: nii näiteks esineb at 67 korral, mis on pisut vähem kui viiendik kõikidest esinemisjuhtudest. Prefiks $p \bar{a} r$ seevastu tuleb ette vaid ühel korral, täpsemalt tabelis 3 .

See järjekord ning üksikute prefiksite esinemissagedus erineb osalt tunduvalt Kuramaa liivi keele prefiksite esinemise vahekordadest. Eriti tähelepanuväärne on prefiksi no suur esinemissagedus Kuramaa liivi keeles (lähemalt allpool).

Tabel 3. Verbiprefiksite esinemissagedus Johann Andreas Sjögreni käsikirjade põhjal

$\begin{array}{lrr}\text { at } & 67 & 17,1 \% \\ \text { iz } & 60 & 15,3 \% \\ \text { pie } & 56 & 14,3 \% \\ \text { aiz } & 43 & 11,0 \% \\ \text { sa } & 43 & 11,0 \% \\ \text { ie } & 42 & 10,7 \% \\ \text { pa } & 31 & 7,9 \% \\ \text { ap } & 28 & 7,2 \% \\ \text { uz } & 18 & 4,6 \% \\ \text { no } & 2 & 0,5 \% \\ \text { pār } & 1 & 0,3 \% \\ & 391 & \end{array}$

e. Prefiksite esinemine on kindlaks tehtud 126 verbi puhul, see võib olla maksimaalselt üks kolmandik kõikidest kindlaks tehtud verbidest. 58 nendest verbidest (46\%) esinevad ainult koos üheainsa prefiksiga (nende asjaolude tõlgendamisest allpool).

f. Verbid, mis esinevad rohkem kui kolme eri prefiksiga, on enamasti liikumisverbid, näiteks (vrd SLW) läed 'minema' (6 prefiksit), utt 'võtma' (6), brouts 'sõitma', (6) pann 'istuma, asetama, panema,' (5), tull 'tulema' (4), vädd 'tõmbama' (4); sealjuures on ka verba dicendi, 
nagu näiteks pagat 'ütlema, rääkima' (5), ütuld 'ütlema' (5) ja kuts 'hüüdma, kutsuma' (4).

5. Neid uurimistulemusi võimaldavad allikad täpsemalt analüüsida. Küll tuleb seejuures arvesse võtta, et kõigi 2180 lause talletaja on Sjögren ning tema ja ta kahe keelejuhi vaheline suhtluskeel oli läti keel. Sjögren ise liivi keelt ei osanud, mistõttu ta oli sunnitud töötama läti keele vahendusel. Allikad jagunevad kahte peaaegu võrdse suurusega ossa, ühelt poolt (=1) Sjögreni lauseteks ja Hupeli eesti mõistatusteks (ühtekokku 981 lauset) ja teiselt poolt $(=2)$ piiblisalmideks ja Hesselbergi lauseteks (ühtekokku 1200 lauset; vrd Winkler/Pajusalu 2016: 16-22): esimesel juhul (1) on Sjögreni enda moodustatud saksakeelsed laused ilmselt kohapeal tõlgi abil läti keelde tõlgitud ja suuliselt keelejuhtidele edasi antud. Seega pole teada, kuidas täpselt tõlk saksakeelsed laused läti keelde tõlkis. Teisel juhul (2) on võimalik kindlaks teha lätikeelsed näidised, mida kirjaoskajatest keelejuhid liivi keelde otse ümber tõlkisid. Need näited on olemas Winkleril/Pajusalul (2016: 115386). See jaotus ühtib laiema, siinses kontekstis tähtsa erinevusega: keeleainese ülestähendamise olud on ühel juhul (1) suulise vestluse näol sundimatu iseloomuga, teisel juhul (2) aga autoriteetse iseloomuga trükitud näidiste tõttu üsna formaalsed.

Kui nüüd verbiprefiksite esinemise vahekordi neid kahte allikatüüpi silmas pidades lähemalt analüüsida, on võimalik kindlaks teha järgnevat:

a. Verbiprefiksite esinemine on esimesel juhul (1) märgatavalt väiksem kui teisel juhul (2):

Tabel 4. Verbiprefiksite osakaal ainestikus

\begin{tabular}{lccc} 
& Prefiksid & Laused & Osa \\
Sjögren & 73 & 885 & $8,2 \%$ \\
Hupel & 6 & 96 & $6,2 \%$ \\
\hline Piibel & 63 & 100 & $63,0 \%$ \\
Hesselberg & 249 & 1100 & $22,6 \%$ \\
\hline Kokku & 391 & 2181 & $17,9 \%$
\end{tabular}

Väikest verbiprefiksite sagedust arvestades võib oma osa esimest tüüpi tekstide puhul (1) olla ühelt poolt tõlgi tehtud tõlke eripäral (Kui hästi oskas ta läti keelt? Kas ta kasutas harva verbiprefikseid?), teiselt poolt võis teatud roll olla ka lausete kvaliteedil, mis mõnikord nende tekstide (1) puhul on lihtsam kui teist tüüpi tekstide (2) puhul. Vaatamata sellele on erinevus kahe tüübi vahel siiski silmatorkav. Tundub, 
et ülalkirjeldatud keeleainese talletamise erinevad olud (kaasa arvatud lätikeelsed näidised ja nende iseloom) on suurel määral põhjustanud sellise tulemuse: ühest küljest oli lähtetekstiks väga autoriteetne piibel, mida püüti tõenäoliselt võimalikult sõnasõnaliselt läti keelest tõlkida, ning teiselt poolt mõistatused, millel on iseenesest juba üsna mänguline iseloom ja mida Sjögren enda sõnul keelejuhi ja tõlgi vahelise suhtluse lihtsustamiseks kasutas.

b. Asjaolu, et prefiksite esinemine on teisel juhul mingil määral tingitud ülestähendamise oludest ja tekstiliigist, lähtub tõsiasjast, et teise osa (2) tekstide puhul on 270 juhul 312-st liivi prefiks identne läti eeskujuga (86,5\%). Kuigi siin puudub võrdlusvõimalus esimese osa tekstidega (1), on kokkulangevuse osatähtsus piisavalt suur selleks, et niisugust tõlgendust toetada.

c. Liivi keele prefiksite läti keele eeskujule toetumise üheks tagajärjeks on see, et ainult üks kord prefiksiga esinevate verbide arv on peaaegu 50\%. Kui prefiksite esinemine oleks liivi keeles tõeliselt juurdunud, siis peaks ühekordselt prefiksiga esinevate verbide arv olema tunduvalt väiksem. Oleks ootuspärane, et need verbid esinevad koos prefiksiga rohkem kui vaid ühe korra.

d. Ka üksikute prefiksite puhul on esimese (1) ja teise (2) osa tekstide vahel erinevused:

\begin{tabular}{|c|c|c|c|c|c|c|c|c|c|}
\hline \multirow[b]{2}{*}{ aiz } & \multicolumn{2}{|c|}{ SJÖGREN } & \multirow[t]{2}{*}{ HuPEL } & \multicolumn{3}{|c|}{ Pilbel } & \multicolumn{3}{|c|}{ HesselberG } \\
\hline & 15 & $20,5 \%$ & & pie & 17 & $27,0 \%$ & at & 43 & $17,3 \%$ \\
\hline at & 12 & $16,4 \%$ & 1 & at & 11 & $17,5 \%$ & $i z$ & 42 & $16,9 \%$ \\
\hline sa & 11 & $15,0 \%$ & 3 & $i z$ & 10 & $15,9 \%$ & pie & 31 & $12,4 \%$ \\
\hline$a p$ & 7 & $9,6 \%$ & & ie & 10 & $15,9 \%$ & aiz & 26 & $10,4 \%$ \\
\hline$i z$ & 7 & $9,6 \%$ & 1 & $s a$ & 6 & $9,5 \%$ & ie & 26 & $10,4 \%$ \\
\hline pie & 7 & $9,6 \%$ & 1 & $a p$ & 3 & $4,8 \%$ & $p a$ & 25 & $10,0 \%$ \\
\hline$i e$ & 6 & $8,2 \%$ & & aiz & 2 & $3,2 \%$ & $s a$ & 23 & $9,2 \%$ \\
\hline$p a$ & 4 & $5,5 \%$ & & $p a$ & 2 & $3,2 \%$ & $a p$ & 18 & $7,2 \%$ \\
\hline$u z$ & 4 & $5,5 \%$ & & $u z$ & 2 & $3,2 \%$ & $u z$ & 12 & $4,8 \%$ \\
\hline no & 0 & & & no & 0 & & no & 2 & $0,8 \%$ \\
\hline$p \bar{a} r$ & 0 & & & $p \bar{a} r$ & 0 & & $p \bar{a} r$ & 1 & $0,4 \%$ \\
\hline & 73 & & 6 & & 63 & & & 249 & \\
\hline
\end{tabular}

Konkreetse tähendusega aiz 'ära' on silmatorkavalt esindatud ainult esimese osa tekstides (1), mitte aga teise osa (2) või Kuramaa liivi keele materjalides. Selle põhjuseks on asjaolu, et Sjögreni laused on konk- 
reetsema tähendusega ja viitavad kohapeal valitsenud keeleainese ülestähendamise oludele ja elutingimustele, samal ajal kui teise osa tekstide (2) laused on reeglina selgelt abstraktsemad.

6. Kui nüüd tõstatada küsimus, kui suures ulatuses olid prefiksid osa Salatsi liivi keele süsteemist, siis peaks keelekogukonna lootusetu olukorra ja läti keele domineerimise tõttu arvama, et prefiksverbid olid juba suures ulatuses liivi keelde tunginud. Sellise tõlgenduse kasuks räägivad erinevad asjaolud.

a. Mõnedele verbidele võib liituda ainult üks prefiks, need verbid on peaaegu alati tekstides just selle prefiksiga määratletud, näiteks $p a$ + veel viel 'lubama, soovima' (6), ie + opp 'õppima' (6) või at + kost 'vastama' (6). Niikaua kui läti eeskuju on käepärast võtta, sisaldavad need verbid alati just neid prefikseid. Taolised juhtumid on seega ilmselgelt juba liivi keele süsteemi ja sõnaraamatu osaks muutunud.

Sellises suunas on võimalik tõlgendada ka tähelepanekut, mille alusel "paljude üksikuna kasutatavate verbide puhul, ... kujutab liitvorm endast ilmekamat väljendit, kusjuures prefiksi ainuke funktsioon on vaid tähendust tugevdava varjundi lisamine" (de Sivers 1971: 81). Üks pilguheit SLW-sse kinnitab seda muljet, näiteks $m \ddot{a} d l$ 'meenutama, meeles pidama', atmǟ dl (sama tähendusega) ja piemädeld (foneetiline variant; samuti sama tähendusega). See räägib selgelt läti keele mõju poolt.

b. Kokku on 30 juhtu (piibel: 2, Hesselberg: 28), kus prefiks erineb läti keele eeskujust. See näitab verbiprefiksite kasutamise teatavat produktiivsust liivi keeles ja seda, et liivi prefiksverbid, nagu de Sivers arvab (vt ülal), arenevad läti keele eeskujust vabanemise suunas.

c. Lisaks leidub 12 juhtu (piibel: 1, Hesselberg: 11), kus läti eeskujus pole prefiksverbi kasutatud, liivi tõlkes aga on seda tehtud. See räägib jällegi prefiksverbide produktiivsuse kasuks.

Siiski on olemas ka kaalukaid tõsiasju, mis räägivad taolise tõlgenduse vastu.

a. 89 juhul läti keele eeskuju kasutab prefiksverbi (kokku 546 juhtumist), mis liivikeelses versioonis puudub. Nii näiteks esineb 'leidma' lätikeelsetes lausetes alati prefiksiga at- (läti at-rast), liivikeelses versioonis aga mitte kunagi.

b. 78 juhul on läti keele prefiksi tähendus omakeelse verbipartikliga (harvadel juhtudel ka määrsõnaga) edasi antud. See käib eriti prefiksite no- ja $p a$ - kohta, millele liivi keeles vastab jera, näiteks läti no-mirt 'surema' ja teiselt poolt liivi jera kuol. See on vastavuses seigaga, et prefiks no- ei esine korpuses pea üldse (vaid kaks korda). See olukord 
erineb prefiksi no- suurest esinemissagedusest Kuramaa liivi keeles (vt ülal), mis selles suhtes tundub palju tugevamini läti keelest mõjutatud olevat. Sarnane juhtum on ka sõna 'jääma', läti palikt: liivikeelsetes versioonides esineb jällegi kas jera või jääb prefiksverb üleüldse tõlkimata.

c. Läti mõju vastu selles räägib lõpuks ka see, nagu ülal mainitud, et suur prefiksite arv on teises tekstide rühmas (2) eriliste keeleainese talletamise olude ja tekstiliikide poolt tingitud.

7. Võtkem ülatoodu kokku. Sellist väidet nagu "põhimõotteliselt võib kõiki verbe prefiksitega kombineerida" (vt punkt 3 ülal) ei ole võimalik Salatsi liivi keele piiratud materjali koguse põhjal toetada, sest puuduvad väidet kinnitavad tõendid. Vaevalt saaks selline väide Kuramaa liivi keeltki iseloomustada. Salatsi liivi keeles on kindlaks tehtud ainult 68 verbi, mis esinevad prefiksiga rohkem kui ühe korra. Kui võtta arvesse, et oluline osa prefiksverbide esinemisjuhte Salatsi liivi keeles on põhjustatud läti keele eeskujust (tekstirühm 2), siis võib oletada, et niimoodi saab seletada suurt osa 58 verbist, mis ainult ühe korra prefiksiga esinevad. Tõeliselt produktiivne eesliitega tuletamine puudutaks sellisel juhul ainult murdosa kõikidest verbidest. Aga ka "rahvakeel", mis de Siversi (vt ülal) väitel eriti palju prefiksverbe kasutab, ei toeta Salatsi liivi keele puhul seda väidet: isegi juhul, kui esimene tekstirühm (1) ei vasta ülestähendamise olude tõttu täielikult "rahvakeele" mõistele, siis ikkagi on see sellele selgelt lähemal kui teine tekstirühm (2). Just esimeses tekstirühmas (1) on aga prefiksverbide esinemissagedus eriti väike. Teiste sõnadega: prefiksverbide olemasolu Salatsi liivi keeles ei saa eitada. Prefiksverbid on aga tunduvalt nõrgemalt esindatud, kui võiks eeldada ühe sureva keele puhul. Suurel osal esinemisjuhtudel pole mingit pistmist Salatsi liivi keele erilise olukorraga (= väljasurev keel), vaid ülestähendamise olude ja tekstiliikidega. Ei saa välistada, et läti keele mõju on selles vallas tegelikult suurem, aga filoloogiline allikate analüüs ei vii sellise järelduseni: suur läti keele mõju ei kajastu prefiksverbide esinemuses tähtsaimates Salatsi liivi keele allikates.

\section{Aadress:}

Eberhard Winkler

Universität Göttingen

Finnisch-Ugrisches Seminar

Heinrich-Düker-Weg 14

37073 Göttingen, Deutschland

E-post: ewinkle@gwdg.de 


\title{
Kirjandus
}

Endzelin, J. (1922) Lettische Grammatik. Riga: Kommissionsverlag A. Gulbis.

Ernštreits, Valts (2013) Liivi kirjakeel. Tartu: Tartu Ülikooli Kirjastus.

Forssman, Bernd (2001) Lettische Grammatik. Dettelbach: J. H. Röll.

LW=Kettunen, Lauri (1938) Livisches Wörterbuch mit grammatischer Einleitung. Helsinki: Suomalais-Ugrilainen Seura.

Mägiste, Julius (1937) “Laenatud indo-euroopa verbiprefikseist läänemere-sm. keelis". Eesti keel 16, 65-85.

de Sivers, Fanny (1971) Die lettischen Präfixe des livischen Verbs. Les prefixes lettons du verbe live. Paris.

de Sivers, Fanny (1971a) Die lettischen Präfixe des livischen Verbs. Anhang: Wörterverzeichnis. Paris.

SjW=Sjögren, Johann Andreas (1861) Joh. Andreas Sjögren's Gesammelte Schriften. Band II, Teil 1: Livische Grammatik nebst Sprachproben; Teil 2: Livisch-deutsches und deutsch-livisches Wörterbuch. Im Auftrag der Kaiserlichen Akademie der Wissenschaften bearbeitet und mit einer historisch-ethnographischen Einleitung versehen von Ferdinand Joh. Wiedemann. St. Petersburg.

SLW=Winkler, Eberhard and Karl Pajusalu (2009) Salis-livisches Wörterbuch. (Linguistica Uralica: Supplementary Series, 3.) Tallinn: Estonian Academy Publishers.

Winkler, Eberhard und Karl Pajusalu (2016) Salis-Livisch I. J. A. Sjögrens Manuskript. Ediert, glossiert und übersetzt von Eberhard Winkler und Karl Pajusalu. (Veröffentlichungen der Societas Uralo-Altaica, band 88.) Wiesbaden: Harrassowitz Verlag.

\begin{abstract}
Eberhard Winkler: Verb prefixes in Salaca Livonian. The article discusses the occurrence of Salaca Livonian verb prefixes based on Andreas Sjögren's data. Considering the relevant studies in Courland Livonian and the fact that Salaca Livonian was already a dying language at the time of Sjögren frequent use of verb prefixes would be expected. However, the analysis shows that on the one hand the use of verb prefixes is not very frequent, on the other hand they can mainly be found in written texts translated directly from Latvian to Livonian: in most cases the prefixes occur in Livonian when they are also presen in Latvian. Moreover, it appears that verb prefixes have been adopted in Salaca Livonian but only to a small extent.
\end{abstract}

Keywords: verb prefixes, Livonian, Salaca Livonian, Courland Livonian 